\title{
Efeito de mudanças no contexto de implementação de uma política multinível: análise do caso da Reforma do Ensino Médio no Brasil
}

\author{
Gabriela Spanghero Lotta 1 \\ Marcela Bauer 1 \\ Rita Jobim ${ }^{2}$ \\ Catherine Rojas Merchán ${ }^{2}$ \\ 1 Fundação Getulio Vargas / Escola de Administração de Empresas de São Paulo, São Paulo / SP - Brasil \\ 2 Instituto Unibanco / Coordenação de Políticas de Ensino Médio, São Paulo / SP - Brasil
}

\begin{abstract}
O artigo busca compreender como mudanças exógenas são afetadas pelos contextos de implementação que encontram em cada local. A partir da análise da Lei 13.415/2017, que reforma o Ensino Médio no Brasil, verifica como as mudanças federais trazidas por esta política provocaram alterações nos estados e qual a variação que os contextos locais geraram na própria reforma. $\mathrm{O}$ artigo se baseia em uma pesquisa qualitativa que acompanhou os efeitos da publicação da Lei e o início do processo de implementação da reforma nos 26 estados e Distrito Federal ao longo de dois anos. O caso empírico foi analisado a partir das variáveis de conflito e ambiguidade que caracterizam os contextos de implementação. Estes achados contribuem para a literatura de implementação de políticas públicas, de reformas e mudanças na administração pública e de políticas de educação.
\end{abstract}

Palavras-chave: implementação de políticas; reformas; ensino médio; mudanças.

\section{Efecto de los cambios en el contexto de implementación de una política multinivel: Análisis del caso de la Reforma de la Educación Media en Brasil}

El artículo busca comprender cómo cambios exógenos son impactados por contextos de implementación establecidos en cada lugar. A partir del análisis de la Ley 13.415/2017, que reforma la Educación Media en Brasil, verifica cómo los cambios federales de esta política provocaron alteraciones en los estados y cómo los contextos locales generaron cambios también a la propia reforma. El artículo se basa en una investigación cualitativa que hizo seguimiento a los efectos de la publicación de la Ley y al inicio del proceso de implementación de la reforma en los 26 estados y el Distrito Federal a lo largo de dos años. El caso empírico fue analizado a partir de las variables de conflicto y ambigüedad que caracterizan los contextos de implementación. El artículo contribuye con la literatura de implementación de políticas públicas, de reformas a la administración pública y de políticas de educación.

Palabras clave: implementación de políticas; reformas; educación media; cambios.

\section{Effects of changes in a multi-level implementation context: analysis of the Brazilian High School Reform}

The article seeks to understand how exogenous changes are impacted by implementation contexts established in each place. Based on the analysis of Law 13.415/2017, which reforms High School in Brazil, it verifies how the federal changes proposed by this policy caused alterations in the states and how the local contexts also generated changes in the reform itself. The article is based on a qualitative investigation that monitored the effects of the publication of the Law and the beginning of the process of implementing the reform in the 26 states and the Federal District over two years. The empirical case was analyzed based on the variables of conflict and ambiguity that characterize the contexts of implementation. The article contributes to the literature on the implementation of public policies, reforms in public administration, and education policies.

Keywords: policy implementation; reforms; high school; changes. 


\section{AGRADECIMENTOS}

A pesquisa que embasa este artigo foi comissionada pelo Instituto Unibanco, a quem agradecemos o apoio técnico e financeiro. Não teria sido possível realizá-la sem o suporte e a parceria do Conselho Nacional de Secretários de Educação (Consed), e especialmente dos técnicos das 27 UFs, que compartilharam os avanços e impasses na implementação das mudanças na política de Ensino Médio. Agradecemos também aos pesquisadores do Núcleo de Estudos da Burocracia (NEB) pelo auxílio na realização das entrevistas.

\section{INTRODUÇÃO}

Políticas públicas estão constantemente sujeitas a mudanças, em maior ou menor dimensão, provocadas por fatores endógenos ou exógenos (Baumgartner, True \& Jones, 1999; Mahoney \& Thellen, 2010). Parte da literatura de políticas públicas tem se debruçado sobre esse fenômeno e seus efeitos na agenda governamental (Sabatier \& Jenkins-Smith, 1993). Em geral, ela analisa como as mudanças causaram alterações na agenda ou na formulação de políticas, na tentativa sistemática de compreendê-las de forma abrangente, comparando diferentes momentos e fatores históricos que podem ajudar a explicar as mudanças (Capella, Brasil \& Sudano, 2015). O que a literatura sugere é que processos políticos têm uma natureza multidimensional em que diversos atores, instituições e ideias interagem na conformação da agenda e das mudanças (Baumgartner, Jones \& Wilkerson, 2011).

Parte da literatura também se dedica a compreender processos de reforma do Estado, observando sua formulação (Osborne \& Gaebler, 1998; Pollitt \& Bouckaert, 2011) e efeitos nas estruturas estatais (Rodrigues \& Jayo, 2016). No entanto, pouco se avançou na compreensão a respeito de como as reformas são implementadas e do efeito do processo de implementação sobre as próprias reformas (Rodrigues \& Lotta, 2017).

Busca-se, neste artigo, contribuir para superar algumas lacunas da literatura, como a compreensão dos resultados das mudanças em realidades complexas, compostas por muitas organizações, nas quais uma mudança exógena pode gerar consequências distintas dependendo do contexto. Outro ponto é o entendimento de como as reformas são implementadas, de quais efeitos a implementação gera sobre elas e em que medida os contextos de implementação as afetam. Pretende-se, portanto, analisar os efeitos da mudança exógena em contextos de implementação de políticas situadas em ambientes institucionais complexos e federativos. As perguntas que se pretende responder neste artigo são: como mudanças exógenas são adaptadas localmente em contextos federativos? Em que medida esses contextos afetam as reformas? Em que medida as reformas afetam diferentes contextos de implementação? Para responder, será utilizada, como modelo analítico, a compreensão de contextos de implementação mediante a relação entre as variáveis conflito e ambiguidade, desenvolvidas por Matland (1995).

Em termos empíricos, escolheu-se como caso a reforma do Ensino Médio no Brasil. Este artigo baseia-se em uma pesquisa qualitativa - entrevistas, estudo de caso e survey - por meio da qual se acompanhou, ao longo de dois anos (2017 a 2018), o início do processo de implementação da reforma nos 26 estados e Distrito Federal, a partir da publicação da Lei 13.415 (2017), tendo sido feitas comparações com o contexto anterior a esta Lei. Este acompanhamento permitiu analisar como os contextos de implementação se transformaram consequentemente à reforma adotada. 


\section{APORTES TEÓRICOS SOBRE PROCESSOS DE IMPLEMENTAÇÃO E MUDANÇA DE POLÍTICAS PÚBLICAS}

Para compreender os processos de implementação e mudança de políticas em um contexto complexo e federativo, foram mobilizados como aportes teóricos os estudos sobre contexto de implementação, sobre implementação de políticas em contextos federativos e sobre implementação de reformas.

\subsection{Contextos de implementação de políticas}

A literatura sobre implementação de políticas debruça-se sobre a análise de como as regras e os planos são concretizados pela ação de diferentes atores (Hill \& Varone, 2016). Parte dessa literatura tem buscado entender as características dos contextos de implementação que permitem que algumas políticas consigam atingir seus resultados e outras, não (Hill \& Hupe, 2003; Pollitt, 2013). Para além de uma visão normativa, procura-se compreender os fatores que afetam o contexto de implementação e, portanto, sua capacidade de alcançar resultados previstos (Faria, 2012; Hill \& Hupe, 2003; Lotta, Nunes, Cavalcante, Ferreira \& Bonat, 2018; Pollitt, 2013). Embora a literatura reconheça a importância do contexto para explicar os processos de implementação, são poucos os autores que avançaram de fato em compreender quais variáveis contextuais importam e como elas afetam a execução das políticas (Pollitt, 2013).

Matland (1995) foi um dos autores que mais orientou os estudos sobre efeitos do contexto sobre a implementação. Inspirado na teoria organizacional, propôs um modelo de análise com base em duas variáveis centrais: ambiguidade e conflito. Para o autor, todo contexto de política pública é marcado por graus diferentes de conflito e ambiguidade; a interdependência entre estes dois elementos leva a contextos mais ou menos propícios a implementações resolutivas e efetivas.

O conflito está relacionado à interdependência entre atores e à (in)compatibilidade de objetivos. Toda organização e política pública carregam incongruências que se materializam em maior ou menor conflito entre atores. O conflito pode ser caracterizado por duas dimensões: conflito com relação aos fins (atores não concordam com os objetivos da política) e conflito em relação aos meios (atores não concordam com as maneiras de atingir os objetivos) (Matland, 1995).

A ambiguidade diz respeito ao espaço dado pela política para interpretação e adaptação tanto com relação aos meios como aos fins (Matland, 1995). Para uma parte dos especialistas, a ambiguidade é um elemento prejudicial às políticas, já que diminui a capacidade de controle, imposição (enforcement) de ações e padronização de resultados (Pressman \& Wildavsky, 1973). Outro segmento considera que a ambiguidade pode ter efeitos positivos, porque permite aprendizado, experimentação e adaptação (Heclo, 1978). Ou seja, ela pode ser um erro do desenho da política, quando esta apresenta falhas nas especificações, abrindo espaço para decisões não previstas e lacunas na democracia (Rothstein, 1998). Também pode ser proposital, quando oportunidades para interpretação indicam que seus autores não querem assumir o risco da predeterminação ou não têm condições políticas para aprovar padrões de serviço (Hill \& Hupe, 2002).

Matland (1995) aponta que ambiguidade e conflito podem existir em diferentes graus e combinações. A associação entre ambos gera contextos de implementação diferenciados, como demonstra o Quadro 1:

REVISTA DE AdMinIStração PÚblica ｜ Rio de Janeiro 55(2): 395-413, mar. - abr. 2021 


\section{QUADRO 1 CONTEXTOS DA AMBIGUIDADE E DO CONFLITO}

\begin{tabular}{l|cr} 
& Baixo conflito & Alto conflito \\
\hline Baixa ambiguidade & Implementação administrativa & Implementação política \\
\hline Alta ambiguidade & Implementação experimental & Implementação simbólica \\
\hline
\end{tabular}

Fonte: Matland (1995, traduzido pelas autoras).

Na implementação administrativa, estão claros os objetivos das políticas e os meios de alcançá-los. São políticas que tenderão a ser executadas de maneira padronizada, por atores com baixo grau de discricionariedade, e cujos resultados serão bastante previsíveis (Matland, 1995; May, 1993). Geralmente, relacionam-se a ambientes tecnocráticos, com baixa politização.

Na implementação experimental, não há questionamento sobre a necessidade da política pública, mas há abertura para se decidir sobre resultados ou formas de alcançá-los. Nestas situações, ocorre o experimentalismo, permitindo aos atores adaptações e interpretações. O foco central é negociação e criação. Está ligada, em geral, a contextos federativos ou de políticas novas; a ambiguidade é proposital para permitir adaptação (Hill \& Varone, 2016; Matland, 1995).

A implementação política acontece em situações em que o governante decide colocar um tema na agenda e implementá-lo, mesmo não tendo resolvido o conflito. Ele cria condições de enforcement por meio de padrões (baixa ambiguidade) (May, 1993). A garantia da conformidade acontece via incentivo ou coerção, levando à superação do conflito (e não ao seu enfrentamento) por meio de formas de implementação padronizadas e top down. Normalmente, são políticas com temáticas conflituosas, mas que fazem parte de uma agenda de governo (Matland, 1995).

Na implementação simbólica, a dificuldade de executar as políticas é evidente, considerando-se que, além de muito ambíguas, são objetos de disputa (Matland, 1995). Esse contexto está ligado, em geral, à existência de novos valores ou objetivos que exigem posicionamento por parte do governo, mas não há mobilização de recursos para colocá-los em prática. Os governantes assumem a temática, mas não enfrentam o conflito nem diminuem a ambiguidade para que a política se efetive. Isso pode acontecer porque o governante não tem interesse em implementá-la, ou as forças de coalizão não dão suporte ou, ainda, não há meios políticos e materiais para fazê-lo. A tendência de políticas desse tipo é de não gerar resultado efetivo (Matland, 1995).

Por ser um dos poucos autores que mobilizam variáveis analíticas para compreender contextos de implementação, Matland (1995) tem sido uma importante referência para estudos sobre o tema e servirá como base analítica para esta pesquisa.

\subsection{Implementação de políticas em contextos federativos}

Uma segunda questão relevante para pensar contextos de implementação diz respeito a como as políticas são adaptadas e reformuladas quando passam pelas múltiplas camadas de atores envolvidos em seus processos. Para analisar a implementação, é importante compreender quem decide sobre o que e como as políticas são alteradas ao longo das camadas decisórias (Hill \& Hupe, 2003). Essa ideia vem do pressuposto de que há, em geral, uma grande distância entre os formuladores das políticas 
e seus executores finais (Arretche, 2001). Tal distância provoca contingências na implementação em virtude de decisões tomadas por uma cadeia de implementadores alocados em contextos políticos e institucionais diversos (Lotta, 2015). Portanto, para compreender os processos de implementação de uma política, é preciso analisar as camadas decisórias pelas quais ela passa.

A literatura propõe dois conceitos centrais: implementação multinível (multi-level) e implementação em múltiplas camadas (multi-layering). A primeira caracteriza quase todas as políticas e diz respeito às diferentes partes que coexistem no ciclo de política pública e que não têm autonomia para alterar decisões. É o caso, por exemplo, das camadas hierárquicas organizacionais envolvidas em uma política (Hill \& Hupe, 2003). Já a implementação multi-layering diz respeito às camadas de diferentes governos que exercem autoridade e têm legitimidade para tomar decisões com autonomia e competência territorial, como acontece nos contextos federativos, em que há uma separação de responsabilidades entre entes com legitimidade decisória (Hill \& Hupe, 2003). Essa distinção é importante porque marca a diferença entre quem tem mandato legítimo para transformar a política e reformulá-la e quem não o tem e, ainda assim, interfere na atuação cotidiana, tentando executar o que foi formulado (Hill \& Hupe, 2003). Quanto mais camadas e níveis, maior a complexidade de implementação, já que a política pode ser alterada nos diferentes espaços e interações (Lotta, 2019).

Camadas e níveis têm uma relação direta com conflito e ambiguidade: a manipulação da ambiguidade das políticas é a tentativa de fazer com que as várias camadas e níveis saibam o que deve ser realizado. A diminuição da ambiguidade tem como efeito a redução da discricionariedade dos atores, o que aumenta a possibilidade de as políticas, ao final, alinharem-se com a proposta original (Lotta, 2019; Matland, 1995). O aumento da ambiguidade dá espaço à reinterpretação das políticas, adequando-as a contextos diversos. Mas gera, como consequência, variação dos resultados. O conflito também pode se dar tanto entre camadas como entre níveis hierárquicos. No primeiro caso, ele faz parte da dinâmica democrática, política e federativa. Já entre níveis hierárquicos, o conflito denota um problema de gestão, em que atores de níveis mais baixos não concordam com decisões tomadas por aqueles de níveis mais altos. Os conflitos podem ser velados - levando a estratégias de sabotagem (Brehm \& Gates, 1997) - ou explícitos, gerando estratégias de insurreição (Mahoney \& Thellen, 2010).

Para colocar uma política em prática, é preciso mapear o grau de conflito e ambiguidade existente e as múltiplas camadas e níveis hierárquicos pelas quais a política irá passar. Com base nesse mapeamento, é possível pensar estratégias de aumento ou diminuição de ambiguidade, enfrentamento ou não de conflito, que permitam executar a política da forma almejada (Hill \& Varone, 2016; Matland, 1995).

Para diminuir a ambiguidade, a saída é aumentar a padronização do desenho das políticas públicas, criando sistemas de incentivo condicionados à conformidade, ou seja, ao atendimento do que foi desenhado em nível central (May, 1995). Quando a ambiguidade diz respeito aos níveis hierárquicos (multi-level), a estratégia pode ser trabalhada com a regulação da discricionariedade dos atores e a criação de sistemas de controle e incentivo para atuação na lógica hierárquica. Já a diminuição de ambiguidade nas camadas federativas depende do fomento da cooperação federativa em torno do desenho das políticas. Nesse caso, Goggin, Bowman, Lester e O'Toole (1990) apontam a saída: para garantir a implementação de políticas públicas em contextos federativos complexos, as mensagens federais devem ser acompanhadas de soluções críveis e viáveis, salientando os problemas e as soluções a serem criadas.

Se a questão passa por atenuar conflitos, a estratégia para os vários níveis é aumentar enforcement e compliance, diminuindo a capacidade de questionamento dos atores hierárquicos (May, 1995). 
Minimizar ambiguidade ou aumentar espaços de negociação são duas estratégias para combater conflitos. Já quando estes dizem respeito aos entes federativos, a estratégia tem de envolver a negociação ou enforcement. Isso é o que May (1995) denomina de adesão via mandatos coercitivos: os governos locais são considerados agentes regulados com a responsabilidade de seguir regras prescritas pelos níveis centrais. Os níveis nacionais decidem padrões e procedimentos para a conquista dos resultados e aplicam sanções a quem não os alcança, diminuindo ambiguidade e forçando a política quando possuem a competência federativa ou quando têm recursos suficientes para gerar adesão "voluntária" com implementação induzida.

As estratégias para gerar adesão (diminuindo conflitos e/ou ambiguidade) passam pelos instrumentos de coordenação e controle, como a elaboração de normativas, sistemas de monitoramento, estratégias de capacitação, incentivos etc. Estes instrumentos tendem a ser coercitivos e mandatórios, como os apontados por May (1993), ou de cooperação entre atores.

Os contextos de produção de políticas são bastante complexos se forem considerados apenas os atores governamentais. No entanto, ao observar a realidade da produção de políticas públicas em democracias atualmente, percebe-se que são raros os governos que as produzem sozinhos (Gomide \& Pires, 2014). No ambiente institucional de produção de políticas públicas, no Brasil, há uma interação intensa entre atores estatais e não estatais. É o caso, por exemplo, dos conselhos de políticas públicas, das conferências, ouvidorias, audiências públicas, dentre outros espaços que institucionalizam a participação social em diversas áreas, incluindo a educação (Gomide \& Pires, 2014; Lotta \& Vaz, 2014; Segatto \& Abrucio, 2016). Para além das instituições participativas, existem diversas formas de coprodução em curso, como a contratação de organizações para provisão de serviços ou de parceiros para desenho e gerenciamento de políticas públicas, atores não estatais que influenciam os processos decisórios.

No caso brasileiro, outra particularidade importante diz respeito a tamanho, heterogeneidade e desigualdade do país. Como aponta a literatura, essas características geram um ambiente de produção de políticas públicas em que se faz necessário um equilíbrio entre o grau de ambiguidade e o grau de coordenação. Por um lado, a alta descentralização - resultado da ambiguidade e baixa coordenação - pode gerar aumento de desigualdades (Abrucio, Franzese \& Sano, 2010; Arretche, 2012). Por outro, a ambiguidade permite produzir experiências inovadoras, importantes para gerar efetividade em nível local. Tem-se buscado este equilíbrio nas últimas décadas por meio de uma combinação entre políticas de incentivo e indução federativa - características de contexto administrativo -, mas com algum espaço para adaptação e criação em nível local - características de contexto experimental (Abrucio et al., 2010; Arretche, 2012; Segatto, 2011).

\subsection{Implementação de reformas}

Outro tema importante para pensar implementação de políticas é o das mudanças institucionais e organizacionais. A literatura aponta dois tipos possíveis de mudança: as radicais, quando ocorre uma alteração abrupta da trajetória, e as graduais, quando se dão alterações incrementais.

Os trabalhos de autores como Baumgartner et al. (1999) e Lindblom (1965) apontam que o funcionamento cotidiano do Estado tende ao incrementalismo, com pequenas mudanças graduais ao longo do tempo, em virtude da dificuldade de enfrentar transformações tanto em termos políticos como pelo alto grau de institucionalização. Isso decorre das características do setor público: dificuldades 
muito complexas; atores com acesso parcial a informações sobre problemas e soluções; processos decisórios que dependem de muita negociação (Lindblom, 1965); e decisões do passado que pesam no presente - denominada path dependence (Pierson, 2000).

Assim, as políticas, em geral, caracterizam-se por longos períodos de estabilidade, interrompidos, eventualmente, por fases de instabilidade, que levam a mudanças significativas (Baumgartner et al., 1999). Tal contexto é denominado pelos autores de equilíbrio pontuado: tendência ao equilíbrio, com pontuações de mudanças radicais que geram novo equilíbrio. Normalmente, mudanças radicais são mais raras e estão relacionadas a fatores exógenos que abalam o status quo institucional - por exemplo, desastres naturais, crises econômicas ou guerras. No entanto, a mudança também pode vir de alterações nas forças de coalizão, que conseguem impor novos padrões, imagens e problemas na agenda política, o que provoca um deslocamento da ação estatal, alterando o equilíbrio anterior para criar um novo ponto de equilíbrio (Baumgartner et al., 1999).

Outro segmento da literatura busca compreender os processos de mudança gradual nas políticas (Lindblom, 1965). Em texto clássico sobre o assunto, Mahoney e Thellen (2010) argumentam que há diversos tipos de mudança nas instituições, que variam de acordo com o grau de profundidade e de transformação institucional. Semelhante à ideia de Matland (1995), eles utilizam o binômio conflito e ambiguidade, mas consideram outras duas variáveis: o número de pontos de veto (conflito) e o grau de discricionariedade dos atores (ambiguidade). Assim, há contextos institucionais com muitos pontos de veto, outros com baixos pontos de veto, além de contextos que permitem alta discricionariedade aos atores, enquanto em outros ela é baixa. A relação entre estes elementos leva a cenários que possibilitam tipos de mudança diferentes.

No caso específico da educação, a literatura tem se voltado à compreensão de condicionantes de sucesso e fracasso da implementação de reformas educacionais. Ao analisar os aprendizados da literatura sobre implementação de reformas no campo da educação, Bruns e Schneider (2016, p. 4, tradução nossa) argumentam que "[...] a reforma educacional é politicamente arriscada". Tendo o risco político como ponto de partida, os autores defendem que as reformas no campo da educação diferenciam-se de outras por quatro características: a ubiquidade e o poder de sindicatos de professores; a opacidade das salas de aula; a dificuldade de monitorar a performance; e o fato de as reformas produzirem resultados a longo prazo. Assim, o sucesso das reformas depende de elementos como: sequência de mudanças; decisão sobre tratar-se de mudança legislativa ou administrativa; estratégias de comunicação adotadas; e negociação com atores com poder de veto, especialmente os sindicatos.

A literatura sobre implementação de reformas educacionais também aponta alguns condicionantes de sucesso: adesão da comunidade escolar, realização de experimentos piloto e/ou em pequena escala e o aprendizado com as falhas de reformas anteriores (Cox, 2006; Holm-Nielsen, Thorn, Brunner \& Balán, 2005; Krawczyk \& Vieira, 2005; Organização para Cooperação e Desenvolvimento Econômico [OCDE], 2010). Parte da literatura também aponta que o sucesso da implementação de uma reforma na educação depende da prioridade que o governo dá tanto ao tema da educação como à reforma em si (Hallinger, 2010; Sorensen, 1994; Tan \& Gopinathan, 2000; Tan, Koh \& Choy, 2016). Por fim, a literatura demonstra que o sucesso de reformas educacionais também depende do tempo dedicado à sua implementação, de forma que os atores estejam convencidos de seu conteúdo e saibam como implementá-lo (Hallinger, 2010; Howie, 2002; Moodley, 2013).

A possibilidade de gerar mudanças ao implementar reformas está vinculada à capacidade de ter propostas que sejam gerais e estratégicas e, ao mesmo tempo, contextualizadas e adaptáveis 
às necessidades locais (Matus, 1996). Este fator é ainda mais relevante em contextos federativos e heterogêneos, como é o caso brasileiro. Nesse caso, o governo federal pode assumir um papel de incentivador e indutor de propostas de mudanças, mas dadas as particularidades de cada contexto e a autonomia local, espera-se que as ideias de reforma sejam transformadas localmente (Segatto, 2011).

Considerando, portanto, a heterogeneidade esperada na implementação de reformas dessa natureza e as características inerentes às reformas apontadas pela literatura, o binômio conflito e ambiguidade torna-se, portanto, ferramenta importante para compreender a capacidade de implementação de reformas na educação. Com base nos referenciais teóricos aqui apresentados, será analisado o recente caso da reforma do Ensino Médio brasileiro, observando os diferentes impactos desse processo nos contextos de implementação.

\section{CONTEXTO E MÉTODOS}

\subsection{Contexto}

Para realizar as análises propostas neste artigo, selecionou-se como caso a implementação da Reforma do Ensino Médio proposta pelo Governo Temer em 2016, por meio da Medida Provisória 748 (2016), posteriormente transformada na Lei 13.415 (2017). A implementação da reforma foi analisada em todos os estados e no Distrito Federal no período de 2017-2018, subsequentemente à aprovação do marco legal federal.

As políticas de educação no Brasil passam por processos de múltiplos níveis e camadas - estas provenientes da divisão de competências garantida pela Constituição Federal (1988), que determina regime de colaboração entre a União, estados e municípios na organização de seus sistemas de ensino. Cabe ao governo federal coordenar a política nacional e articular os diferentes níveis federativos (art. 8). Os governos estaduais devem assegurar o Ensino Fundamental e oferecer, com prioridade, o Ensino Médio (art. 10). No entanto, as normas gerais das políticas (como a Lei de Diretrizes Básicas [LDB], a Base Nacional Comum Curricular [BNCC]) são definidas nacionalmente. A divisão de competências na educação não é estanque, havendo sobreposição de ofertas em diferentes redes e um desequilíbrio em termos de distribuição de recursos (Segatto \& Abrucio, 2016).

Além de ser uma política multi-layering, a educação também é caracterizada por múltiplos níveis que se reproduzem nos três entes federativos. De forma concreta, trata-se de dezenas de secretarias estaduais, milhares de secretarias municipais, de unidades regionais, de escolas e milhões de servidores.

Ou seja, é um contexto multinível complexo, heterogêneo e historicamente desigual (Segatto \& Abrucio, 2016), que acumula alta discricionariedade decisória. Assim, pensar processos de mudança nessa realidade significa desenvolver sistemas de adesão multinível com muitos atores que, em geral, não atuam de forma hierárquica. Como apontam Bruns e Schneider (2016, p. 44, tradução nossa), “[...] para serem efetivas, as reformas precisam chegar até mesmo nas salas de aula mais distantes, o que significa que podem ter que passar por múltiplos níveis da hierarquia administrativa, incluindo diretores regionais".

Além disso, o caso do Ensino Médio reflete o ambiente institucional brasileiro. Em virtude do federalismo e da descentralização das políticas sociais, a educação no Brasil funciona por meio de um complexo emaranhado de atores localizados nos três níveis federativos, além de atores sociais, instituições participativas e outros poderes que interferem no processo decisório (Segatto \& Abrucio, 
2016). Com isso, pode-se argumentar que, por princípio, a implementação de reformas na educação brasileira pressupõe ampla negociação e construção de coalizões, enfrentando obstáculos para sua promulgação e para mudanças posteriores, que teriam de ser submetidas aos mesmos pontos de veto e de parceiros (Schneider \& Mizala, 2014). Nesse contexto, é relevante analisar a implementação de uma reforma e seus efeitos.

\subsection{Método de coleta e análise}

As análises apresentadas neste artigo baseiam-se em duas estratégias de pesquisa: levantamento da literatura sobre implementação de políticas e levantamento de dados primários relacionados ao processo de implementação de mudanças no Ensino Médio nos estados brasileiros ${ }^{1}$. Os dados foram coletados em duas etapas: entrevistas e pesquisa de campo em onze estados, em 2017; survey, entrevistas e análise documental nos 26 estados e no Distrito Federal, em 2018.

Para as entrevistas e pesquisa de campo de 2017, foram selecionados onze estados: Acre, Pará, Piauí, Rio Grande do Norte, Pernambuco, Bahia, Espírito Santo, Minas Gerais, Ceará, Santa Catarina, mais o Distrito Federal. A escolha ${ }^{2}$ das unidades federativas buscou contemplar estados que já vinham apostando em mudanças no Ensino Médio antes da reforma de 2016. Nestes estados, a coleta de dados se deu por meio de entrevistas com os técnicos responsáveis pelo Ensino Médio de cada Secretaria. No caso dos estados do Ceará e Santa Catarina, foram realizadas também visitas de campo, em que se entrevistaram outros atores relevantes ao processo de implementação, como representantes do conselho estadual de educação, professores, diretores de escolas e representantes do sindicato. A escolha destes dois estados deu-se por sua relevância em termos de inovação de políticas educacionais nos anos anteriores, o que permitiria compreender como as reformas foram negociadas e implementadas em estados que o fizeram de forma mais substantiva.

Esta primeira etapa de coleta de dados permitiu um mapeamento dos processos de mudança adotados até 2017 em parte dos estados brasileiros.

Em 2018, adotaram-se outras estratégias de levantamento de dados, abrangendo os 26 estados e o Distrito Federal: 1) aplicação de um survey, em parceria com o Conselho Nacional de Secretários de Educação (Consed); 2) realização de entrevistas com técnicos responsáveis pelo Ensino Médio nos estados. O objetivo do survey era mapear e compreender o desenvolvimento das iniciativas de mudanças e de flexibilização curricular nos estados brasileiros. Foram levantados dados relativos às mudanças em curso em cada estado - se já havia mudanças legais, se elas incorporavam as principais medidas propostas pela Lei 13.415 (2017), o número de escolas impactadas, os atores envolvidos nas discussões etc.

As entrevistas, realizadas entre julho e outubro de 2018, tinham como propósito: validar e completar os dados coletados pelo survey; compreender mudanças qualitativas; e testar hipóteses. Foram realizadas 40 entrevistas com técnicos responsáveis pela coordenação do Ensino Médio nas Secretarias Estaduais de Educação dos 27 estados. Como em alguns estados a gestão do Ensino Médio se divide entre Secretaria de Educação e Secretaria de Desenvolvimento (ou afins), ou em

\footnotetext{
${ }^{1}$ A pesquisa foi desenvolvida com apoio técnico e financeiro do Instituto Unibanco.

${ }^{2}$ A escolha dos estados foi feita por meio de apoio técnico do Instituto Unibanco e do Conselho Nacional de Secretários de Educação (Consed).
} 
departamentos diferentes dentro da Secretaria de Educação, em alguns casos foram realizadas mais de uma entrevista por estado. Todas foram transcritas e analisadas de forma a gerar narrativas para contextualizar e aprofundar o entendimento sobre o movimento de mudança em cada estado.

Em seguida, partiu-se para as análises dos processos de mudança à luz da literatura de implementação de políticas. Com base no modelo analítico de Matland (1995), observaram-se variáveis de ambiguidade e conflito em cada momento temporal (pré e pós-2016) para compreender os contextos de implementação. Feito isso, foram realizadas as análises que respondem às perguntas de pesquisa deste artigo. O objetivo não era compreender os casos de forma particular, mas sim o movimento geral da reforma, observando o país como um todo. Assim, e em acordo com os entrevistados, optou-se por não citar casos específicos e preservar o nome dos técnicos que cooperaram com a pesquisa.

\section{ANÁLISE DO CONTEXTO DE POLÍTICAS DE EDUCAÇÃO NO BRASIL: PRÉ E PÓS-REFORMA}

\subsection{Contexto pré-reforma}

Ao observar empiricamente as ações desenvolvidas pelos estados em relação a mudanças no Ensino Médio antes de 2016, foram identificadas duas características concomitantes: 1. contexto de implementação experimental e 2. contexto de implementação administrativa.

O primeiro era reflexo das características federativas da educação, que geravam baixo conflito entre os atores e alta ambiguidade das regras, garantindo que cada estado gestasse as próprias soluções. No entanto, a consequência do contexto experimental em um país com alta diversidade e desigualdade é a produção da heterogeneidade na provisão de políticas de educação (Arretche, 2012). Onde há capacidades instaladas, os estados e municípios conseguem produzir soluções inovadoras, includentes, adequadas ao local. Onde faltam capacidades, estados e municípios têm problemas de execução e não conseguem efetividade. Assim, essa heterogeneidade, por um lado, produz experiências inovadoras, mas, também, irregulares, com resultados de baixa e alta efetividades, levando à desigualdade no acesso e na qualidade da educação (Abrucio et al., 2010).

Para dar conta dos problemas de desigualdade, o governo federal, nas últimas décadas, passou a fortalecer as políticas de incentivo e indução que buscam estimular padrões de produção e resultado de políticas, com o repasse de recursos específicos ao que foi definido nacionalmente (Abrucio et al., 2010; Arretche, 2012). É o típico caso de cooperação intergovernamental descrito por May (1993) e que leva à construção de um contexto de implementação administrativa (Matland, 1995), com a tentativa de conseguir adesão, induzindo ações padronizadas para a construção de capacidades locais.

Em ambos os casos, seja no contexto experimental, seja na implementação administrativa, a característica central dos cenários de implementação de mudanças no Ensino Médio nos estados era de baixo conflito, uma vez que existia um grau de estabilidade nas interações entre os diferentes atores, que apresentavam grande autonomia para tomada de decisões. Assim, gerava-se um processo gradual de transformações, como apontado pelos técnicos entrevistados: processos de mudança na provisão de Ensino Médio caracterizados por experimentação, diálogo com os diversos atores e um esforço para a produção de novos resultados, em geral, antecedendo a mudança institucional.

Uma parcela dos governos estaduais estava vivenciando esses processos por camadas, conversão e reinterpretação na implementação, com desvios por alterações no ambiente, sem ter de enfrentar uma 
mudança radical das leis (Mahoney \& Thellen, 2010). Como exemplo, pode-se citar a implementação de inovações curriculares nas escolas de tempo integral, de forma dialogada com os atores diretamente envolvidos e com espaço para ajustes e correções de rotas. Tal vivência era possibilitada pelo ambiente relativamente estável, pelo domínio dos estados sobre formas de fazer e pela consolidação prévia de um ambiente experimental e heterogêneo. Por exemplo: Espírito Santo, com reorganização curricular e experiências do mundo do trabalho desde 2007; Rio Grande do Sul (desde 2012) e Rio de Janeiro (desde 2011), com um novo currículo; Ceará, com experiências de Escolas de Ensino Médio em Tempo Integral (EMTI) e ensino técnico profissional, além de reorganização curricular, desde 2008; e Pernambuco, com EMTI desde 2008, e experiências de flexibilização curricular desde 2012.

\subsection{Reforma do Ensino Médio: mudança de contexto de implementação}

A análise dos dados empíricos permite afirmar que, se o ambiente institucional até 2016 era marcado por relativa estabilidade e baixo conflito entre os atores, não se pode dizer o mesmo do ano seguinte. Em 2016, houve o impeachment da presidente Dilma Roussef e a entrada de um presidente com baixa legitimidade social. Este propôs uma medida provisória, depois aprovada na Lei 13.415 (2017), concretizando várias mudanças propostas anteriormente, mas, também, introduzindo novas, pouco debatidas. Houve, portanto, uma quebra do equilíbrio prévio, criando uma conjuntura crítica em que um ator muda o status quo e o ambiente de estabilidade (Baumgartner et al., 1999).

A lei em questão propôs alterações e regulamentações para o Ensino Médio por meio de novas redações de artigos da LDB. Embora acarretassem várias mudanças do ponto de vista normativo, as alterações não eram automaticamente aplicáveis aos contextos locais: precisariam ser regulamentadas e depois implementadas pelos estados. A título de exemplo, algumas das principais modificações foram: ampliação de carga horária; mudanças na estrutura curricular; alteração nas regras para formação de docentes; mudanças na oferta de educação profissional e técnica; incentivos à oferta de educação em tempo integral, dentre outras.

Boa parte da reforma não foi regulamentada na ocasião, gerando falta de clareza sobre como as alterações deveriam ocorrer. Criou-se, assim, um novo ambiente de conflitos, com ambiguidade em virtude de regras ainda não interpretadas e sem direcionamento sobre sua execução - como a incerteza sobre a aprovação da BNCC do Ensino Médio e a falta de orientações para implementar itinerários formativos.

De um lado, a reforma levou o contexto da política a um alto conflito, na medida em que foi aprovada e estabelecida por um governo não legitimado por uma parcela da sociedade, sem levar em conta debates graduais anteriores. De outro lado, por não ter sido plenamente regulamentada, e por criar mudanças não consensuais, a reforma gerou um contexto de alta ambiguidade. Temos, portanto, o deslocamento de um contexto que variava entre implementação experimental e implementação administrativa para o de alta ambiguidade e alto conflito. Tal contexto é denominado de implementação simbólica, aquela em que não se esperam resultados, já que o conflito dificulta a mobilização de atores e a alta ambiguidade paralisa a capacidade de ação (Matland, 1995). Nesse caso, foram criados ambiguidades e conflitos tanto em relação a meios como a fins.

Em paralelo, o governo federal continuou operando na lógica de incentivos e induções, ou seja, de uma implementação administrativa, mas com medidas relativas à reforma do Ensino Médio, como a Política de Fomento à Implementação de Escolas de Ensino Médio em Tempo Integral (EMTI), 
reforçada naquele período. Esta política previa o repasse de recursos do Ministério da Educação (MEC) para os estados no prazo de dez anos por escola, isto é, foram criadas condicionalidades para o repasse pelo MEC.

Ou seja, ao mesmo tempo que se deu um deslocamento da política geral para a zona de implementação simbólica (conflito e ambiguidade), linhas específicas permanecem na lógica de implementação administrativa via sistemas de incentivo e indução (Arretche, 2012; Matland, 1995).

Tendo em vista esse novo contexto, as questões que ficam são as seguintes: para os estados, qual o efeito desse deslocamento? Em que medida a mudança exógena, causada pela instância federal, produziu resultados distintos nos diferentes estados brasileiros? A seguir, analisam-se comparativamente as unidades federativas, buscando compreender as diferentes consequências causadas pela reforma.

\section{MUDANÇAS EXÓGENAS EM CONTEXTOS LOCAIS: EFEITOS DA REFORMA NOS ESTADOS}

Ao analisar comparativamente o Ensino Médio nos estados, verificou-se uma situação marcada por muita heterogeneidade, tanto pelo grau das mudanças operadas, como pelo sentido que elas tinham e a temporalidade de sua implementação.

Analisando os dados empíricos sobre as mudanças de Ensino Médio pré-MP 748 (2016) e Lei 13.415 (2017), foi possível caracterizar os estados em dois grupos, de acordo com o grau de incidência, abrangência e institucionalização das mudanças praticadas. O primeiro refere-se aos que tiveram experiências prévias incipientes de mudança no Ensino Médio. O segundo inclui os estados que tiveram experiências que podem ser consideradas mais significativas e/ou impactantes, ou seja, representavam alterações mais radicais, mais institucionalizadas ou com maior abrangência na rede.

O segundo grupo ainda se divide em dois subgrupos: estados com experiências prévias institucionalizadas, mas pontuais ou vinculadas a temas específicos induzidos pelo governo federal; e estados que tinham um movimento mais consolidado de mudanças, com iniciativas inter-relacionadas, mais abrangentes, institucionalizadas e não apenas vinculadas aos incentivos federais.

Ao comparar estes grupos levando-se em conta o contexto anterior a 2016 e o de 2018, foram encontrados diferentes tipos de trajetórias criadas em consequência dos contextos prévios, resumidos no Quadro 2:

\section{QUADRO 2 IMPACTOS DA REFORMA DO ENSINO MÉDIO NOS ESTADOS}

\begin{tabular}{|c|c|c|}
\hline & Alto impacto da reforma & Baixo impacto da reforma \\
\hline $\begin{array}{l}\text { Estados com } \\
\text { experiências prévias } \\
\text { incipientes. }\end{array}$ & $\begin{array}{l}\text { 1. Estados com poucas experiências prévias } \\
\text { de mudança, fortemente impactados pela } \\
\text { reforma (na quantidade ou no conteúdo). } \\
\text { Fazem parte deste grupo dois estados. }\end{array}$ & $\begin{array}{l}\text { 2. Estados com poucas experiências prévias de } \\
\text { mudança, em que o impacto da reforma é proporcional } \\
\text { à adesão aos sistemas de indução do governo federal. } \\
\text { Fazem parte deste grupo doze estados. }\end{array}$ \\
\hline $\begin{array}{l}\text { Estados com fortes } \\
\text { experiências prévias. }\end{array}$ & $\begin{array}{l}\text { 3. Estados com experiências significativas } \\
\text { antes da reforma, nos quais a Lei impulsiona } \\
\text { mudanças. Fazem parte deste grupo seis } \\
\text { estados. }\end{array}$ & $\begin{array}{l}\text { 4. Estados com experiências significativas integradas, } \\
\text { caracterizando um movimento mais abrangente, nos } \\
\text { quais a Lei não impulsiona mudanças em virtude da } \\
\text { complexidade anterior. Fazem parte deste grupo sete } \\
\text { estados. }\end{array}$ \\
\hline
\end{tabular}

Fonte: Elaborado pelas autoras. 
No primeiro grupo, incluem-se estados que decidiram aproveitar o momento da reforma para impulsionar mudanças mais abrangentes, seja em termos quantitativos (aumentar o número de escolas em tempo integral para além daquelas incentivadas pelo governo federal, por exemplo), seja em qualitativos (investir em novas modalidades e currículos ou aumentar a relação com atores da rede). Baseando-se nesse grupo, é possível concluir que a indução do governo federal é capaz de viabilizar mudanças importantes na agenda dos estados, mas alavancadas quando há iniciativas locais próprias para investir em transformações além dessa indução.

No segundo grupo, com a chegada da reforma, iniciativas prévias incipientes foram impactadas por mudanças já esperadas pelos incentivos, sem inovação no conteúdo ou abrangência. Em todos eles, o maior impacto causado foi a criação de EMTI, que, em geral, traz consigo um conjunto de iniciativas que promovem a flexibilização, a formação integral e o protagonismo do estudante, mas que não necessariamente provocam transformações mais estruturais. Esse grupo permite perceber que, quando o governo federal propõe alterações vinculadas a modelos de indução (implementação administrativa), ele é capaz de colocar a mudança na agenda dos estados, uma vez que estes tenham interesse em aderir. Mas, diferente do primeiro grupo, é perceptível menor presença de conteúdos locais próprios, o que significa mudanças mais aderentes ao que é proposto pelo governo federal, com uma trajetória mais linear e esperada. Esse cenário indica que uma mudança exógena pode reposicionar as ações internas de forma incremental quando os estados aderem a ela.

O terceiro e quarto grupos são diferenciados pelo grau de institucionalização e integração entre as mudanças. O terceiro é composto por unidades federativas com experiências prévias importantes, mas, em geral, vinculadas a outras ações de indução operadas pelo governo federal em períodos anteriores. Essas transformações, embora mais robustas, não constituíram um movimento único, mas um conjunto de iniciativas somadas e pouco institucionalizadas. Nesses estados, a chegada da reforma consistiu em uma alavancagem para mudanças. Em quase todos, desde 2012 (alguns casos ainda nos anos 2000), havia movimentos voltados a revisões curriculares, criação de escola profissional técnica integrada em turno único, experiências de jornada complementar e integração com o mundo do trabalho e criação de disciplinas eletivas, todos potencializados por ações do governo federal na década anterior (Programa Ensino Médio Inovador [ProEMI]). Nesses casos, é interessante notar como esse processo, mais ampliado e consistente, pode dispor de uma mudança exógena para alavancar a transformação. Isso ocorre porque, em grande medida, as inovações criadas estavam em consonância com o modelo da reforma, uma vez que acompanharam historicamente o movimento sugerido pelo governo federal via estratégias de incentivo e indução, tornando menos custosa a adoção das novas mudanças.

Por fim, o quarto grupo também vivia um processo amplo e intenso de mudanças no Ensino Médio. No entanto, sofreu um efeito menor, ou efeitos de paralisação ou diminuição de ritmo de mudanças com a chegada da reforma. É interessante notar que, em todos os estados desse grupo, há uma tradição prévia de inovações e bons resultados na educação, com importantes legados e capacidades institucionais. Neles, a agenda de mudanças no Ensino Médio já estava posta há bastante tempo, promovida não apenas pelas diretrizes federais (como no grupo anterior), mas pela própria trajetória da educação que empreenderam. Trata-se de estados que, por exemplo, tinham inovado na criação de EMTI há mais de uma década, aprovado modelos de reorganização curricular, de oferta de educação profissional em turno único, dentre outros. Em todos havia um processo de transformação em curso, com rumo claro, objetivos estabelecidos, um modelo próprio e alta institucionalização 
das mudanças. Neles, a aprovação da MP 748 (2016) e da Lei 13.415 (2017) tornou-se um potencial obstáculo. Por um lado, porque criou um ambiente de indecisões, gerando paralisia (por exemplo, a indefinição quanto ao Ensino Médio na BNCC). Por outro, porque perceberam o alto custo de adaptação das medidas já implementadas às novas propostas. Em suma, nesses estados, a reforma não foi, até 2018, uma alavanca. Pelo contrário, transformou-se em um motivo para um clima de "calma e cautela", ou seja, de espera em relação aos acontecimentos para, posteriormente, adaptar as mudanças já consolidadas.

Outro ponto importante sobre a trajetória das mudanças diz respeito ao processo de normatização, que influencia o grau de institucionalização. Os estados do grupo 4 investiram nos últimos anos em processos amplos, de forma abrangente. Os pertencentes aos outros três grupos apresentam variações na normatização: alguns fizeram normas para mudanças pontuais, já outros nada fizeram por entender que se tratava de um momento de experimentação ou debate. Isso ajuda a explicar, mais uma vez, as dificuldades de implementação das mudanças no grupo 4.

\section{CONSIDERAÇÕES FINAIS}

Este artigo teve como objetivo estudar os efeitos que uma mudança exógena pode provocar no contexto de implementação de políticas públicas em ambientes institucionais complexos e federativos. Em termos empíricos, analisou-se o início do processo de implementação da reforma do Ensino Médio, entre 2017-2018, para observar em que medida as decisões tomadas pelo governo federal alteraram os contextos de implementação dos estados e, ao mesmo tempo, em que medida os contextos locais também alteraram os efeitos da reforma. Como base analítica, foram utilizadas as variáveis conflito e ambiguidade.

A análise dos casos permitiu ver como a transformação de contexto levou os atores a um estado de implementação simbólica, gerando paralisia e baixa capacidade de ação. Ao mesmo tempo, as iniciativas de incentivo e indução, operadas pelo governo federal, provocaram situações de implementação administrativa. Esses dois contextos gerais se materializaram de formas distintas nos estados. Isso se deve ao fato de as mudanças exógenas encontrarem contextos específicos em cada localidade, levando, assim, a resultados diferentes.

Esse caso também reflete as complexidades de contextos de implementação multi-level e multilayering, em que há vários atores presentes, com interesses diversos e necessidades de coordenação. Demonstra, ainda, como, nestes casos, os instrumentos de coordenação tornam-se peças-chave na efetivação de decisões. Como aponta a literatura sobre reformas na educação, se há uma lição a ser aprendida com todos os casos é que a fase de implementação das reformas é crucial e altamente vulnerável, especialmente sem o envolvimento de atores interessados no processo decisório, como ocorreu no Brasil (Bruns \& Schneider, 2016). A literatura também mostra como a falta de antecipação da contestabilidade e de envolvimento de atores-chave leva os conflitos para outros contextos, inviabilizando parte da implementação. Como apontam os dois autores, "[...] perdedores na fase de promulgação sabem que terão oportunidades mais tarde para tentar influenciar nas reformas" (tradução nossa). Embora não tenha sido feita uma análise da posição dos vários atores perante a reforma, é possível perceber, apenas da perspectiva dos atores dos governos estaduais, que reformas não negociadas, cujo conflito e ambiguidade não são resolvidos, tendem a gerar efeitos distintos em cada contexto, conforme a reação dos atores locais. 
É importante considerar, ainda, que neste artigo fez-se a análise de um período específico do movimento de reforma (entre 2017 e 2018) e que tanto governos estaduais como o governo federal seguiram investindo de alguma maneira nas estratégias de implementação, buscando diminuir conflitos e ambiguidades ${ }^{3}$. Mas, considerando o momento estudado, o resultado dessas ações não pode ser observado. Assim, um limite neste artigo é compreender um período restrito do tempo, que deveria ser ampliado em pesquisas futuras. Outros estudos também poderiam aprofundar a análise dessas mudanças de contexto debruçando-se sobre casos específicos, para entender como e por que ocorreram diferenças de implementação nos estados e como os distintos atores se comportaram nesses cenários diversos.

Os achados aqui apresentados contribuem tanto para a literatura de implementação de políticas públicas como para a de educação, assim como para a literatura que discute reformas e mudanças no setor público. Empiricamente, também se pretende contribuir para o entendimento sobre o processo de mudança no Ensino Médio brasileiro após a publicação da Lei 13.415 (2017).

\footnotetext{
${ }^{3}$ O Programa de Apoio ao Novo Ensino Médio, institucionalizado por meio das Portarias no 649 de julho de 2018 e no 1.024 , de 4 de outubro de 2018, e o Guia de Implementação do Novo Ensino Médio são medidas que buscam orientar a implementação por meio da diminuição de ambiguidades e conflitos.
} 


\section{REFERÊNCIAS}

Abrucio, F., Franzese, C., \& Sano, H. (2010). Coordenação e cooperação no federalismo brasileiro: avanços e desafios. In A. S. Cunha, L. A. Medeiros \& L. Aquino (Org.), Estado, instituições e democracia (v. 1., pp. 177-212). Brasília, DF: IPEA.

Arretche, M. (2001). Uma contribuição para fazermos avaliações menos ingênuas. In $\mathrm{M}$. C. R. N. Barreira, \& M. C. B. Carvalho (Org.), Tendências e perspectivas na avaliação de políticas e programas sociais. São Paulo, SP: IEE/PUC, Cenpec, Cedac.

Arretche, M. (2012). Democracia, federalismo e centralização no Brasil. Rio de Janeiro, RJ: Fundação Getulio Vargas/Fiocruz.

Baumgartner, F., Jones, B. D. \& Wilkerson, J. (2011). Comparative Studies of Policy Dynamics. Comparative Political Studies, 44(8), 947-972.

Baumgartner, F., True, J. L., \& Jones, B. D. (1999). Punctuated equilibrium theory: explaining stability and change in American policymaking. In P. Sabatier (Ed.), Theories of the policy process. Oxford, UK: Westview Press.

Brehm, J., \& Gates, S. (1997). Working, shirking, and sabotage: Bureaucratic response to a democratic public. Ann Arbor, MI: University of Michigan Press.

Bruns, B., \& Schneider, B. (2016). Managing the politics of quality reforms in education: policy lessons from global experience. Background Paper: The Learning Generation, (Working Paper prepared for International Commission on Financing Global Education Opportunity). Nova York, NY. Recuperado de http://report.educationcommission. org/wp-content/uploads/2017/01/Managing-thePolitics-of-Quality-Reforms.pdf

Capella, A., Brasil, F., \& Sudano, A. (2015). O estudo da agenda governamental: reflexões metodológicas e indicativos para pesquisas (pp. 1-43). In Anais do $39^{\circ}$ Encontro Anual da ANPOCS, Caxambu, MG.

Constituição da República Federativa do Brasil: Promulgada em 5 de outubro de 1988. (1988). Brasília, DF. Recuperado de http://www.planalto.gov. br/ccivil_03/constituicao/constituicao.html
Cox, C. (2006). Policy formation and implementation in secondary education reform: The case of Chile at the turn of the century. Washington, DC: World Bank.

Faria, C. (2012). Implementação de políticas públicas: teoria e prática. Belo Horizonte, MG: PUC Minas.

Goggin, M, Bowman, A., Lester, P., \& O’Toole, L., Jr. (1990). Implementation theory and practice: Toward a third generation. Glenview, IL: Scott Foresman/ Little, Brown.

Gomide, A., \& Pires, R. (Eds.). (2014). Capacidades estatais e democracia. Arranjos institucionais de políticas públicas. Brasília, DF: IPEA.

Hallinger, P. (2010). Making education reform happen: is there an "Asian" way? School Leadership \& Management, 30(5), 401-418.

Heclo, H. (1978). Issue networks and the executive establishment. In A. King (Ed.), The New American Political System. Washington, DC: American Enterprise Institute.

Hill, M., \& Hupe P. (2002). Implementing Public Policy: Governance in theory and practice. Londres, UK: Sage Publications.

Hill, M., \& Hupe, P. (2003). The multi-layer problem in implementation research. Public Management Review, 5(4), 471-490.

Hill, M., \& Varone, F. (2016). The public policy process. Londres, UK: Routledge.

Holm-Nielsen, L. B., Thorn, K., Brunner, J. J., \& Balán, J. (2005). Regional and international challenges to higher education in Latin America. In H. Wit, I. C. Jaramillo, J. Gacel-Ávila, \& J. Knight (Ed.), Higher education in Latin America (pp. 39-69). Washington, DC: World Bank.

Howie, S. J. (2002). Renewal of secondary education curricula and assessment in South Africa. In World Bank (Ed.), Secondary education in Africa: Strategies for renewal (pp. 41-53). Washington, DC: World Bank.

Krawczyk, N. R., \& Vieira, V. L. (2005). Um estudo sobre o estado da arte da reforma educacional na década de 90 na América Latina: Brasil, Argentina, Chile e México (Relatório de pesquisa). São Paulo, SP: FAPESP. 
Lei n. 13.415, de 16 de fevereiro de 2017. (2017). Altera as Leis n. 9.394, de 20 de dezembro de 1996, que estabelece as diretrizes e bases da educação nacional, e 11.494, de 20 de junho 2007, que regulamenta o Fundo de Manutenção e Desenvolvimento da Educação Básica e de Valorização dos Profissionais da Educação, a Consolidação das Leis do Trabalho - CLT, aprovada pelo Decreto-Lei no 5.452, de 1 de maio de 1943, e o Decreto-Lei no 236, de 28 de fevereiro de 1967; revoga a Lei no 11.161, de 5 de agosto de 2005; e institui a Política de Fomento à Implementação de Escolas de Ensino Médio em Tempo Integral. Brasília, DF. Recuperado de http:// www.planalto.gov.br/ccivil_03/_ato2015-2018/2017/ lei/l13415.htm

Lindblom, C. (1965). The Science of Muddling Through. Public Administration Review, 19(2), 79-88.

Lotta, G. (2015). Burocracia e implementação de políticas de saúde. Rio de Janeiro, RJ: Fiocruz.

Lotta, G. (Org.). (2019). Teoria e análises sobre implantação de políticas públicas no Brasil. Brasília, DF: ENAP.

Lotta, G., Nunes, A., Cavalcante, S., Ferreira, D., \& Bonat, J. (2018). Por uma agenda brasileira de estudos sobre implementação de políticas públicas. Revista do Serviço Público, 69(4), 779-816.

Lotta, G., \& Vaz, J. (2015). Arranjos institucionais de políticas públicas: aprendizados a partir de casos de arranjos institucionais complexos no Brasil. Revista do Serviço Público, 66(2), 171-194.

Mahoney, J., \& Thellen, K. (2010). Explaining institutional change: Ambiguity, agency and power. Cambridge, MA: Cambridge University Press.

Matland, R. (1995). Synthesizing the implementation literature: The ambiguity-conflict model of policy implementation. Journal of Public Administration Research and Theory, 5(2), 145-174.

Matus, C. (1996). Estratégias políticas: Chimpanzé, Maquiavel e Gandhi. São Paulo, SP: Fundap.

May, P. (1993). Mandate design and implementation: Enhancing implementation efforts and shaping regulatory styles. Journal of Policy Analysis and Management, 12(4), 634-663.

May, P. (1995). Can cooperation be mandated? Implementing intergovernmental environmental management in New South Wales and New Zealand. Publius: the Journal of Federalism, 25(1), 89-114.

Ministério da Educação \& Conselho Nacional dos Secretários de Educação. (2018). Guia de Implementação do Novo Ensino Médio. Brasília, DF: Autor.

Moodley, G. (2013). Implementation of the curriculum and assessment policy statements: challenges and implications for teaching and learning (Dissertação de Mestrado). University of South Africa, Pretoria, South Africa.

Organização para a Cooperação e Desenvolvimento Econômico. (2010). Ontario, Canada: Reform to support high achievement in a diverse context. Paris, França: OECD Publishing.

Osborne, D., \& Gaebler, T. (1998). Reinventando o governo: como o espírito empreendedor está transformando o setor público. Brasília, DF: MH Comunicação.

Pierson, P. (2000). Increasing returns, path dependence and the study of politics. American Political Science Review, 94(2), 251-267.

Pollitt, C. (Ed.). (2013). Context in public policy and management: The missing link? Cheltenham, UK: Edward Elgar Publishing.

Pollitt, C., \& Bouckaert, G. (2011). Public management reform: A comparative analysis - New public management, governance, and the Neo-Weberian State. Oxford, UK: Oxford University Press.

Portaria $n^{\circ}$ 649, de 10 de julho de 2018. (2018). Institui o Programa de Apoio ao Novo Ensino Médio e estabelece diretrizes, parâmetros e critérios para participação. Brasília, DF. Recuperado de https://www.in.gov.br/materia/-/asset_publisher/ Kujrw0TZC2Mb/content/id/29495231/do12018-07-11-portaria-n-649-de-10-de-julhode-2018-29495216

Portaria $n^{\circ} 1.024$, de 4 de outubro de 2018. (2018). Define as diretrizes do apoio financeiro por meio do Programa Dinheiro Direto na Escola às unidades escolares pertencentes às Secretarias participantes do Programa de Apoio ao Novo Ensino Médio, instituído pela Portaria MEC no 649, de 10 de julho de 2018, e às unidades escolares participantes da avaliação de impacto do Programa de Fomento às Escolas de Ensino Médio em Tempo Integral - EMTI, instituída pela Portaria MEC no 1.023, de 4 de outubro de 2018. 
Brasília, DF. Recuperado de https://www.in.gov. br/materia/-/asset_publisher/Kujrw0TZC2Mb/ content/id/44100315/do1-2018-10-05-portaria-n1-024-de-4-de-outubro-de-2018-44100107

Pressman, J., \& Wildavsky, A. (1973). Implementation: How great expectations in Washington are dashed in Oakland. Berkeley, CA: University of California Press.

Rodrigues, D., \& Jayo, M. (2016). Modernização administrativa em contexto subnacional. Estudo de caso do Detran-SP. Cadernos Gestão Pública e Cidadania, 21(68), 61-83.

Rodrigues, D., \& Lotta, G. (2017). Análise do processo de implementação de reformas em organizações públicas: os casos do Poupatempo e do Detran-SP. Cadernos Gestão Pública e Cidadania, 22(72), 214-237.

Rothstein, B. (1998). Just institutions matter. Cambridge, MA: Cambridge University Press.

Sabatier, P., \& Jenkins-Smith, H. (1993). Policy change and learning: the advocacy coalition approach. Boulder, CO: Westview Press.

Schneider, B., \& Mizala, A. (2014). Negotiating education reform: Teacher evaluations and incentives in Chile (1990-2010). Recuperado de https://doi. org/10.1111/gove.12020

Segatto, C. (2011). Como ideias se transformam em reformas: um estudo comparativo das mudanças educacionais orientadas pelo desempenho nos estados brasileiros (Dissertação de Mestrado). Escola de Administração de Empresas de São Paulo/FGV, São Paulo, SP.

Segatto, C., \& Abrucio, F. (2016). A cooperação em uma federação heterogênea: o regime de colaboração na educação em seis estados brasileiros. Revista Brasileira de Educação, 21(65), 411-429. Recuperado de https://doi.org/10.1590/s1413-24782016216522

Sorensen, C. W. (1994). Success and education in South Korea. Comparative Education Review, 38(1), 10-35.

Tan, C., Koh, K., \& Choy, W. (2016). The education system in Singapore. In S. Juszczyk (Ed.), Asian Education Systems. Toruñ, Polônia: Adam Marszalek Publishing House.

Tan, J., \& Gopinathan, S. (2000). Education reform in Singapore: Towards greater creativity and innovation. NIRA Review, 7(3), 5-10. 


\section{Gabriela Spanghero Lotta}

https://orcid.org/0000-0003-2801-1628

Professora e pesquisadora de Administração Pública e Governo da Fundação Getulio Vargas (FGV); Doutora em Ciência Política pela USP, mestre e graduada em administração pública pela FGV; Coordenadora do Núcleo de Estudos da Burocracia (NEB); Docente da Escola Nacional de Administração Pública, ENAP; Pesquisadora do Centro de Estudos da Metrópole (CEM); Bolsista produtividade 2 do CNPQ; Coordenadora da Área Temática Estado e políticas públicas da Associação Brasileira de Ciência Política (ABCP); Diretora da pesquisa da Associação Nacional de Ensino e Pesquisa do Campo de Públicas (ANEP/CP).

E-mail: gabriela.lotta@gmail.com

\section{Marcela Bauer}

https://orcid.org/0000-0002-9752-4067

Mestre em Administração Pública e Governo pela Fundação Getulio Vargas (FGV); Especialista em metodologias de pesquisa e graduada em Ciências Sociais pela Pontifícia Universidade Católica de São Paulo (PUC-SP).

E-mail: marcela.bauer@gmail.com

\section{Rita Jobim}

https://orcid.org/0000-0003-2917-7531

Coordenadora de Políticas do Ensino Médio do Instituto Unibanco; Mestre em Literatura Brasileira pelo Departamento de Letras da Pontifícia Universidade Católica do Rio de Janeiro (PUC-Rio); Graduada em Produção Editorial pela Escola de Comunicação da Universidade Federal do Rio de Janeiro (ECO/UFRJ) e em Letras pelo Departamento de Letras da Pontifícia Universidade Católica do Rio de Janeiro (PUC-Rio). E-mail: ritajobim@hotmail.com

\section{Catherine Rojas Merchán}

https://orcid.org/0000-0001-5771-7342

Atua na Coordenação de Políticas de Ensino Médio do Instituto Unibanco; Mestre em Administração Pública e Governo pela Fundação Getulio Vargas (FGV); Graduada em Governo e Relações Internacionais pela Universidad Externado da Colômbia. E-mail: catherinerojasmerchan@gmail.com 